\title{
Flexible Pavements and Climate Change: A Comprehensive Review and Implications
}

\author{
Yaning Qiao ${ }^{1} \mathbb{D}$, Andrew R. Dawson ${ }^{2} \mathbb{D}$, Tony Parry ${ }^{2}$, Gerardo Flintsch ${ }^{3}$ and Wenshun Wang ${ }^{1, *}$ \\ 1 School of Mechanics and Civil Engineering, China University of Mining and Technology, Xuzhou 221116, \\ China; yaning.qiao@cumt.edu.cn \\ 2 Nottingham Transportation Engineering Centre (NTEC), Department of Civil and Environmental \\ Engineering, University of Nottingham, Nottingham NG7 2RD, UK; \\ andrew.dawson@nottingham.ac.uk (A.R.D.); tony.parry@nottingham.ac.uk (T.P.) \\ 3 Center for Sustainable Transportation Infrastructure, Virginia Tech Transportation Institute (VTTI), \\ Department of Civil and Environmental Engineering, Virginia Polytechnic Institute and State University, \\ Blacksburg, VA 24061-0131, USA; gflintsch@vtti.vt.edu \\ * Correspondence: kdwangws@cumt.edu.cn; Tel.: +86-151-9067-0169
}

Received: 27 December 2019; Accepted: 23 January 2020; Published: 2 February 2020

\begin{abstract}
Flexible pavements and climate are interactive. Pavements are climate sensitive infrastructure, where climate can impact their deterioration rate, subsequent maintenance, and life-cycle costs. Meanwhile, climate mitigation measures are urgently needed to reduce the environmental impacts of pavements and related transportation on the macroclimate and microclimate. Current pavement design and life cycle management practices may need to be modified to adapt to changing climates and to reduce environmental impacts. This paper reports an extensive literature search on qualitative and quantitative pavement research related to climate change in recent years. The topics cover climate stressors, sensitivity of pavement performance to climatic factors, impacts of climate change on pavement systems, and, most importantly, discussions of climate change adaptation, mitigation, and their interactions. This paper is useful for those who aim to understand or research the climate resilience of flexible pavements.
\end{abstract}

Keywords: pavement; climate change; performance; maintenance; life cycle cost; adaptation; mitigation

\section{Introduction}

Evidence from previous studies has shown that the climate is changing. For example, global surface temperature has increased $0.85^{\circ} \mathrm{C}$ between 1880 and 2012, and the rate of change has become more rapid in the most recent decades. Meanwhile, the sea level has been rising globally and extreme weather events, e.g., floods, hurricanes, and heat waves, have become more frequent in many regions. Climate change will likely continue, at least into the near future [1].

In the United States, $94 \%$ of paved roads are flexible pavements. These pavements have almost always been designed and maintained with the assumption of historical local climatic conditions. As challenges from climate change arise, it is of importance to adapt pavement infrastructure to these changes. Flexible pavements are a type of environmentally sensitive infrastructure. When environmental conditions change negatively, pavement deterioration can occur faster and vice versa. In regions where the negative changes will occur, additional costs may be incurred by road authorities to address this. If nothing is done, costs will be borne by the users in terms of losses such as fuel consumption, safety, and time. On a national level, this means the sum of costs incurred due to climate change may become significant, and additional budgets will be needed for climate adaptation and mitigation in the future. 
Hence, it is an urgent task to incorporate climate resilience into pavement design and management; however, there are important questions that must first be answered, including (1) How do pavements and climate interact? (2) What is the research trend for assessing impacts of climate change on flexible pavements? (3) How does climate change impact flexible pavement systems (including performance, maintenance, and costs) in a pavement life cycle perspective? (4) What are the current research gaps regarding climate adaptation and mitigation for flexible pavements?

To answer these questions, this paper attempts to present a comprehensive literature review synthesizing the current understanding of the interactions between climate change and flexible pavement systems, particularly in terms of climate adaptation and mitigation. The authors consulted various literature research engines including Web of Science, Scopus, Transportation Research International Documentation (TRID), and Google Scholar. An extensive literature search was conducted, using the keywords "climate change", "temperature", "moisture", "sea level rise", "cloud", "wind", "life cycle assessment", "life-cycle cost analysis", "climate adaptation", or "climate mitigation", in combination with "flexible pavement". A final list of 141 publications (publication types: papers/reports/books/theses/standards/websites) were selected for this study. The majority of them have been published in the past decade. The selection criteria primarily included the number of citations, of relevance to this study, and each publication's quality [2]. The expert judgment of authors was used to determine the relevance and qualities of these publications. Finally, the authors synthesized and compared characteristics (e.g., qualitative or quantitative research, the methodology utilized, key conclusions, and limitations) of the selected publications. Despite the care taken to achieve a comprehensive review, some relevant publications with merit may still have been omitted due to the limitation of the utilized search engines, document types, search language, keywords, etc.

The remaining part of this paper is arranged as follows. First, the "Background" section is presented to help readers to establish a conceptual sequence of impacts of climate (change) on pavement systems. It starts by reviewing the known responses of pavement infrastructure to environmental factors. Then, a critical review of research methodology is conducted. The critical review primarily examines recent studies on impacts of climate change on pavement performance, maintenance, and costs for both qualitative and quantitative perspectives. Next, popular climate adaptation and mitigation methods are described and discussed. The interactions between climate change adaptation and mitigation are subsequently discussed. For adaptation and mitigation, rather than conducting an extensive review of specific adaptation and mitigation measures, this paper focuses on the general methodological approaches and their principles, emphasizing the gaps to be bridged and research areas that need to be further investigated.

This paper can serve as a "hitch-hiker's guide" for agencies, road users, researchers, and practitioners to understand climate change adaptation and mitigation of flexible pavements from a systematic perspective. It also serves as a synthesis of the existing knowledge regarding what is known and what is not known related to climate resilient and sustainable flexible pavements. Eventually, gaps in the current research are identified with recommended future research areas.

\section{Background}

\subsection{Flexible Pavements and Climate Change}

In general, climate change can have a direct impact on environmental conditions and, therefore, change pavement performance. The energy and moisture balance of a pavement can be disturbed by climate stressors, and the long-term pavement performance (rate of deterioration) will change as a consequence (i.e., the direct impact). From the literature, the most common climate stressors include temperature, precipitation, groundwater, cloud cover, and wind speed [3]. Typically, pavement performance is most influenced by temperature and moisture, and the long-term impacts from the climate stressors can be significant $[4,5]$. 
Climate change can also have indirect impacts on flexible pavements. Indirect impacts are principally from demographic changes caused by climate-related migrations, but also may include such factors as changes in vegetative shade due to growth differences resulting from climate change [6]. Climate change related migration is believed to have an influence on the population of certain regions and the change of local traffic demand [7]. Traffic, especially heavy vehicles, is a main source of pavement damage [8]. Consequently, the indirect impact of climate change on the performance of flexible pavements can be significant. Unfortunately, predictions of changes in traffic demand due to specific climate change are currently uncertain or even impossible to predict.

\subsubsection{Temperature}

Pavement temperature is dependent on energy balance, particularly on the pavement surface. The pavement absorbs heat from solar energy, which is nearly constant over the service life of pavements (typically 20-40 years). The reflection coefficient (albedo) of a pavement surface plays a significant role in absorbing solar energy, which can have a dominant influence on maximum pavement temperature $[9,10]$. Some energy leaves the pavement by radiation and convection, and the magnitude of convective heat loss depends on air temperature and wind speed. Heat is conducted through asphalt layers to the layers beneath. Heat capacity and thermal conductivity of pavement materials are important properties that determine the temperature profile in the pavement $[2,9,11]$. The re-emission by paved areas, by convection or radiation, of previously absorbed heat is a significant contributor to the urban heat island effect; therefore, albedo and the pavement materials' thermal characteristics are themselves indirect contributors to local warming [12].

It has been widely accepted in the pavement research field that temperature mainly impacts the asphalt layers, where increases in temperature can reduce the stiffness of asphalt materials, which can limit the stress-strain response of the pavement and reduce the ability of a pavement structure to spread loads [3]. In addition, even if the change in the stiffness of these materials is not significant over the length of a single day, changes in stress-strain response and load spreading ability can exhibit their effects in the long term and may accelerate load-related deterioration. Furthermore, the ability of asphalt materials to resist permanent deformation reduces as temperature increases [13-15]. In extreme cases, when temperature has significant daily/hourly increases, accelerated development of permanent deformation can be expected $[3,16]$. Increases in the temperature ranges due to climate change can increase thermal stresses in asphalt layers, and more thermal cracking can be expected $[17,18]$. In addition, higher temperature can lead to faster aging of asphalt mixtures, and pavements can become more prone to cracking due to brittleness [19-21].

\subsubsection{Precipitation and Groundwater}

Precipitation and groundwater can impact pavements by changing moisture levels in pavements. In practice, moisture can enter and exit pavements in different ways [22,23]. Rainfall will drain away from a pavement by uncontrolled runoff or via drainage infrastructures (gullies, drains, and pipes). Surface runoff can enter a pavement's structure from its sides and through cracks and potholes. Groundwater level varies in different seasons and can be influenced by precipitation, flooding, and, in coastal areas, by storm surge and sea level rise [23-25]. Moisture content in the unbound granular layers and subgrade can be significantly affected by the groundwater level in regions where the existing groundwater level is high. Due to flooding or heavy rain, the pavement subgrade or even unbound layers may be submerged, resulting in significant moisture levels. Water in the pavements can also move in the form of vapor in capillaries, depending on temperature [22]. Therefore, evaporative potential may be significantly increased in areas where droughts may occur.

Moisture mainly influences unbound and soil materials and adhesion between bitumen and aggregates. With an increase in the degree of saturation, the resilient modulus of unbound and subgrade materials can decrease significantly [23]. Moisture can also have an influence on the rutting resistance of the subgrade $[4,26]$. The shear strength of unbound and subgrade material may reduce 
significantly at high levels of saturation, which can cause permanent deformation to accumulate rapidly and, under extreme circumstances, lead to the collapse of the materials (an exponential increase of permanent deformation) $[27,28]$. In addition, unbound and subgrade materials with a greater proportion of fine materials are more susceptible to moisture damage [23].

Moreover, moisture can also impact asphalt concrete materials [29]. Stripping (raveling) at the asphalt surface can be caused by various factors, such as poor materials, construction, environmental factors, traffic, or a combination of one or more of these factors. It was found that saturation in asphalt layers (e.g., after a rainfall) can accelerate stripping [30-32]. This is probably because excessive moisture in asphalt layers allows pore pressures to develop under trafficking, which can disrupt the aggregate-bitumen adhesion [33]. In regions where precipitation (or even flooding) will increase, stripping may become more frequent, especially when drainage is inadequate.

\subsubsection{Freeze-Thaw Cycles}

The freeze-thaw phenomenon is caused both by temperature and moisture in cold regions. Low temperature in winter freezes moisture into ice lenses that defrost during spring. In some soils, extended freezing acts to draw up more water into lower pavement layers from below. Excessive moisture can then be released on thawing, which remains trapped in the pavement until thawing is complete. This often occurs in unbound layers and subgrade soils so that a significant reduction in resilient modulus and rutting resistance can be expected. A reduction in resilient modulus of between $48 \%$ and $63 \%$ due to spring-thaw was found in previous research [34]. Severe pavement distress may occur during the spring-thaw period $[2,14,23,27]$.

Climate change can impact freeze-thaw cycles in many ways. Firstly, climate change can prolong thaw periods in some regions and lead to extended periods of high moisture content in pavements, which results in more rapid development of distress such as rutting and stripping. Longer spring load restrictions may then have to be applied in such regions, resulting in consequential economic loss due to limited accessibility, detours, and reduced local business [35]. Secondly, climate change may delay the beginning of seasonal frost and potentially lead to more freeze-thaw cycles, possibly due to a reduction in the depth of the snowpack [36]. Such climate change can eliminate freeze-thaw in some regions with mild winters. In this case, the result may be reduced pavement deterioration in spring. However, many businesses in northern climates depend on freezing months to harvest wood or to travel on local roads without load restrictions, e.g., New England in the U.S. Without a freeze, these pavements may be significantly damaged if load restrictions are not put in place or the pavement structures reconstructed. Access to some forests may be, in effect, curtailed.

\subsubsection{Cloud Cover}

Cloud cover can impact the shortwave and longwave radiation and affect the energy balance on pavement surfaces [37]. On the one hand, cloud cover can directly influence the amount of solar radiation (i.e., shortwave radiation) incident with Earth's surface and hence with pavement surfaces, which may be absorbed or reflected. Increases/decreases of cloud cover can also influence air temperatures and further impact pavement temperatures. On the other hand, cloud cover can reflect surface radiation (i.e., longwave radiation) back down to the Earth's surface (and hence to pavement surfaces) by a back radiation mechanism. In areas where cloud cover will significantly increase in the future, pavements may tend to cool down due to a decrease in shortwave radiation. However, in compensation, there will be increases in longwave radiation to slow down the cooling process.

\subsubsection{Wind Speed}

Wind speed affects the heat convection from pavement surfaces. It is generally considered that increasing wind speed can reduce pavement surface temperatures and, thus, is beneficial for pavements (assuming very low temperatures are not involved). Qin and Hiller found that wind speed can vary pavement temperatures between $2{ }^{\circ} \mathrm{C}$ and $10{ }^{\circ} \mathrm{C}$ [38]. The variation is greater when the 
surrounding air temperature is higher, e.g., at midday or on a sunny day. Extreme wind (e.g., a tornado or hurricane) may bring debris and damage a pavement; however, this is out of the scope of this study and, thankfully, rare.

\subsection{Sensitivity of Pavement Performance to Climate Stressors}

The significance of various climate stressors differs with regards to pavement performance. Many studies have been performed to evaluate the sensitivity of pavement performance indices to climatic factors, using the Mechanistic-Empirical Pavement Design Guide (MEPDG) [38-43]. The MEPDG is a pavement performance prediction tool considering factors including traffic, pavement structure, material, and environmental factors. The environmental factors have been considered using the Enhanced Integrated Climatic Model (EICM) [44]. The EICM can "translate" weather to pavement environmental conditions (e.g., temperature and moisture profiles), which are then used to calculate material responses and predict long-term performance.

The sensitivity of pavement performance to climatic factors is usually nonlinear and, thus, needs to be analyzed for each specific case. However, there are a few general observations. Most research has demonstrated that temperature is the most influential climate stressor for pavement performance [43,45]. Qiao et al. [41] examined the sensitivity of pavement performance to climate stressors on three typical highway sections in three regions of the U.S. that are likely to be subject to the impacts of climate change. It was discovered that both the average annual temperature and temperature range can be influential. This conclusion is supported by Yang et al. [43] and Li et al. [45], using a similar approach. Precipitation was not found to be influential [45]. On the other hand, Qiao et al. [46] found that precipitation can sometimes be as influential as temperature for pavements with a high groundwater level. Percent sunshine (i.e., cloud cover) and wind speed can be influential, but not as influential as temperature $[43,45]$.

In summary, these studies indicated that temperature, temperature ranges, and groundwater level may be critical climate stressors for pavements. Thus, the long-term/extreme changes of temperature (e.g., local warming or more frequent heat waves) and high groundwater level (e.g., due to flooding, storm surge, or sea level rise) are of particular concern. Other factors (including precipitation, wind speed, and sunshine percentage) are not found to be as influential as temperature or groundwater level. Their impacts are insignificant most of the time and are usually neglected in analyses. However, as a state-of-the-art tool, there is no scientific evidence to prove that the MEPDG is always accurate in predicting pavement performance in the light of climate variability. Thus, the uncertainties in the pavement performance and the consequent effects on any sensitivity analysis need to be further quantified [47,48].

\subsection{Interactions: Climate, Pavement Performance, Maintenance and Costs}

Interdependency exists in the pavement system in the phases of design, construction, maintenance, operation, and disposal. Climate change will not only impact pavement deterioration but also these other phases. Therefore, it is important to understand the interaction of climate change and the pavement from a systematic perspective in order to develop cost effective and environmentally friendly adaptation and mitigation methods. An attempt to describe the interactions is shown in Figure 1.

The input variable to the pavement system is climate change and the outputs include the consequent changes in deterioration, maintenance, costs, and environmental impacts. The direct impacts (as represented by arrow ' $a$ ' in Figure 1) and indirect impacts (arrows 'b' and ' $c$ ') of climate change need to be considered in the design phase of flexible pavements. For the direct impact, climate change needs to be considered, especially in areas where climate will become hotter, colder, wetter, dryer, and more extreme. Climate change can even cause impassibility, e.g., some coastal roads may be flooded due to the sea level rise. The demographic changes due to climate change (the indirect impacts), are likely to impact traffic volume in some locations and, thus, are also expected to have profound effects on pavement performance and, hence, the requirements at design, operation, maintenance, 
and renewal stages. Traffic redistribution across the network as desirable places to live and work change (due to climate change) may have a greater influence than the direct climate change impacts [7].

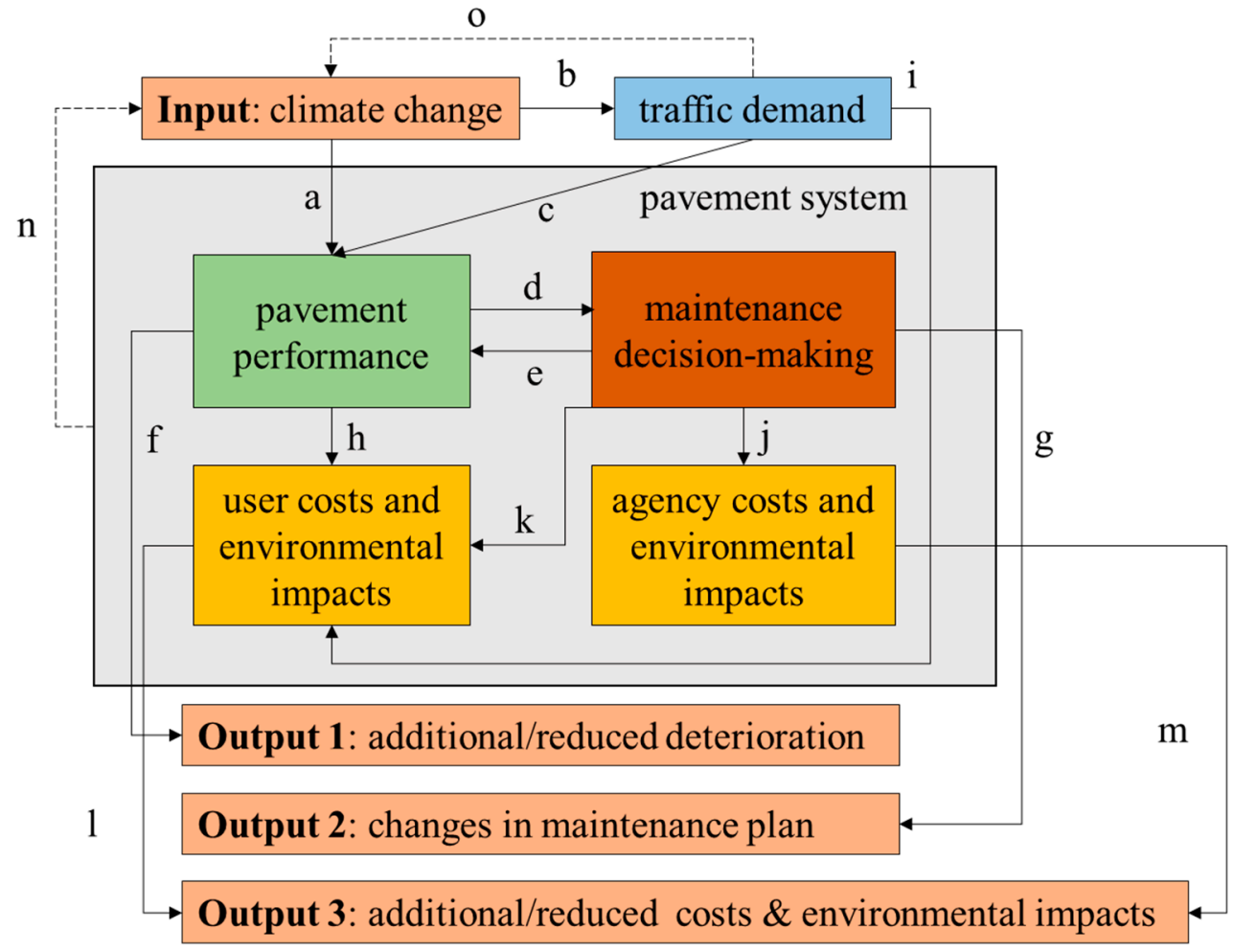

Figure 1. Interactions: climate, performance, maintenance, and costs $[46,49,50]$.

In practice, pavement maintenance and rehabilitation (M\&R) decision-making are performed based on pavement performance levels (arrow 'd'), e.g., indicated by the International Roughness Index (IRI), rutting and cracking [51-53]. Different M\&R treatments have different maintenance effects and can return pavements to various performance levels (arrow 'e') [54]. In addition, different materials applied in the treatments may have a different ability to resist further deterioration (e.g., thermal cracking) [55]. As pavement performance can be impacted by climate change (Output 1: arrow ' $f$ ' in Figure 1), maintenance decision-making may need to adapt to the changes as a consequence (Output 2: arrow 'g' in Figure 1) [56]. For example, more (or less) "intensive" maintenance (e.g., corrective maintenance instead of the historic preventive maintenance) may need to be chosen to address the additional deterioration. Eventually, life-time pavement performance impacts the user costs and environmental impacts (arrow ' $h$ ') [57]. For example, road user fuel consumption and emissions are higher on a rougher road and, thus, they can be impacted by climate change that causes increased pavement deterioration. It can also be affected by changes in traffic demand (arrow ' $i$ '). In practice, maintenance decision-making is constrained by the agencies' maintenance budget and how different maintenance interventions have different costs and environmental impacts (arrow ' $j$ '). Furthermore, more frequent maintenance can result in more delays and lead to greater work zone user costs, e.g., delay costs, detour costs, and fuel consumption costs (arrow ' $k$ ') [58]. Therefore, more intensive maintenance, although addressing the additional deterioration due to climate change, will need to be justified by budget and life-cycle costs (LCC) (arrows ' 1 ' and ' $m$ '). Furthermore, of course, these environmental impacts have a consequential impact on future climate change, so the decisions taken earlier by users and agencies in the light of climate change have a 2-way consequence on both the response to and the cause of climate change. In addition, some of the elements in this figure have a climate change mitigation (or generating) effect (e.g., arrows ' $\mathrm{n}$ ' and ' $\mathrm{o}$ '). These will be discussed later in Section 3.7 . 


\section{Review of Research Methodology}

\subsection{Qualitative Assessment Method}

The qualitative method applies risk assessment methods that seek to describe the combined consequences of changes to a climate stressor (e.g., change in frequency or severity of a certain climate stressor) on both the highway infrastructure and transport. Particular attention is given to highways where future increases in high or low temperature, intensive precipitation, and frequency of flooding are predicted to be significant [59]. Qualitative studies are commonly performed to evaluate the potential risk of climate change on highways at a network level, to identify regions for investigation, and to discuss adaptation and mitigation methods [60-63].

With specific topography, climatic, and hydrological information of the region, these studies can identify significant climate stressors, such as more frequent extreme hot weather, flooding, hurricanes, and extended thaw periods. Extreme weather events, which are difficult to predict in quantitative ways, are often assessed using qualitative studies, although downscaling techniques are sometimes employed for a semi-quantitative approach (see Section 3.2). The qualitative research topics are usually informative and have wide applications. Nevertheless, it has been recommended that quantitative methods such as economic evaluation and risk assessment should be conducted to quantify costs and risks associated with climate change $[64,65]$.

Qualitative research is important to understand the interactions between climate and pavements, to identify regional climate stressors, and to recognize climate-related vulnerability in pavement design and management. In addition, qualitative analyses can be used to identify direct/indirect pathways of disruption to which climate change may lead, not only of physical pavement infrastructure, but also, through interconnections, of social factors such as human health, behavior, habits, and decisions [66]. However, none of the studies can quantify the amount of additional damage caused by climate change and the additional cost for adaptations and mitigation. They are usually applied along with quantitative methods.

\subsection{Quantitative Assessment Method}

With the development of climate prediction tools, predictions of future climate such as daily temperature and precipitation can be available both at global and local scales. Together with the development of pavement performance prediction models (e.g., the MEPDG), they enable quantitative research to assess the impact of climate change on pavement performance. For example, Tighe et al. [39] and Mills et al. [40] modelled the impact of climate change on pavement performance in Canadian cities using the MEPDG. It was concluded that longitudinal cracking, alligator cracking, and rutting will be exacerbated by climate change, and maintenance will have to be performed earlier to mitigate the impact. While accounting for site specific traffic conditions, climate models, and pavement thickness (arrows ' $a$ ' and 'c' in Figure 1), these studies used generalized material properties for asphalt layers. Incorporating locally calibrated asphalt properties (e.g., asphalt mixture dynamic modulus testing and thermal properties) may improve the accuracy of pavement performance predictions and thus the reliability of the results [2]. Li et al. [49] developed a framework to assess the impact of climate change on flexible pavements (indicated by arrow ' $a$ ' in Figure 1) and estimated calibration factors for modifying MEPDG performance predictions to account for climate change. This study developed an easy and feasible way to incorporate the impacts of climate change into mechanistic-empirical pavement design. In addition, the results of these studies indicated the necessity of investigating the subsequent maintenance and Life Cycle Cost (LCC) analysis due to climate change. However, the utilized MEPDG calibration factors are "coarse" and may contain large uncertainties when applied to other different pavement sections, due to the limited number of cases validated. Mndawe et al. [67] simulated the pavement's life due to extra moisture content caused by climate change in South Africa. They concluded that variabilities in precipitation and, thus, in soil moisture, can reduce road design 
reliability, although the climate change signal may be minimal in terms of precipitation. Similar studies were also conducted for the USA, Canada, and Egypt [68-73].

While most of these studies focus on the quantifying impacts of climate change on pavement performance, only a few studies considered improving the reliability of future climate prediction by using statistical downscaling methods. These methods use historical weather observations to remove the bias in global/regional climate model output, which can better represent local extreme climates. Meagher et al. [42] proposed a method to assess the impact of climate change on pavement deterioration by using downscaled regional climate models. This study developed a method to match the Cumulative Distribution Function (CDF) of predicted climate with the CDF of historical climate data. Nega et al. [74] applied statistically downscaled climate data to predict pavement temperature and then distresses under future climates. Even though the downscaling techniques are computationally efficient, flexible, and able to process a large number of global climate scenarios in a limited amount of time, statistical downscaling assumes that the current relationship (e.g., CDF) between local climate and large-scale climate model output does not change in the future.

Further consideration has been given to the impacts of climate change on the economic consequences of accelerated or decelerated deterioration and changed service life due to climate change. Such studies are usually conducted either at section levels or at the network level. The section-level studies usually explore the consequent changes in life-cycle cost components caused by climate change. For example, a section-level assessment framework to evaluate the impact of climate change on pavement maintenance and LCC was developed with project level case studies [46]. This study applied pavement performance prediction with climate change projection as input and performed an analysis to obtain the subsequent maintenance decision-making triggers and LCC (considered arrows ' $a$ ', ' $d$ ', ' $e$ ', ' $h$ ', ' $j$ ', and ' $k$ ' in Figure 1). Road user costs, as an important component of LCC, were considered in this study. Notably, it was concluded that climate change can not only increase costs but may, under some circumstances, reduce road user costs and LCC. This is because the increasing frequency of adaptive maintenance under future climate may improve the life-cycle performance levels and thus save significant user costs (e.g., fuel consumption and abrasion costs) as the road will be smoother after maintenance. The study suggested that user costs are important and need to be considered in assessing the impact of climate change on the economic performance of highways. Section-level studies show advantages in using material-specific performance modelling under different climate scenarios and can account for the life-cycle economic impacts to discover cost components that can be significantly influenced by climate change. However, the economic estimations are only targeted at specific combinations of climate, structure, maintenance, and traffic pattern in a specific region and, thus, the results are likely to remain limited in scope [48].

Furthermore, many studies attempted to quantify the impacts of climate change on highway systems at network levels. Austroads [75] conducted a study to investigate future changes in climate, Thornthwaite moisture index, and pavement life-cycle costs in Australia. As one of the earliest and most comprehensive literatures on climate change and pavements, this study provided an assessment of climate change in Australia in 100 years and its impacts on pavement deterioration and costs. It also identified adaptive measures in construction and maintenance, considering demographic changes (not necessarily only associated with climate change as arrow ' $b$ ' in Figure 1). However, it was reported that pavement performance prediction may be inaccurate due to a lack of local calibration. Therefore, the estimated cost may need to be revised with calibrated models (see arrows ' $d$ ' and ' $j$ ' in Figure 1). In 2009, the World Bank developed a framework to quantify highway adaptation costs associated with climate change [76]. In a climate change resilience assessment of the African continent, a budget of 180 billion U.S. dollars was estimated for African roads to adapt to climate change [77]. An opportunity cost approach was applied in the study, and this budget estimation can be used to claim climate change adaptation budgets. Schweikert et al. [78] used an Infrastructure Planning Support System (IPSS) to assess the fiscal costs of climate change for highways, which considered adaptation costs. This method is capable of predicting costs with and without adaptation. Although comprehensive, a limitation in 
these network level studies is that they may not have sufficient engineering details (neglecting the pavement performance box in Figure 1), including interactions among pavement structure, material, traffic, and additional details that must be considered [48].

Houghton and Styles [79] reviewed work undertaken by the Australian Road Research Board (ARRB) on the long-term impact of climate change on major road infrastructure in Australia. The ARRB used future climate projections to evaluate highway life-cycle costs using a Highway Development and Management Model (HDM-4) (considered as arrows ' $a$ ', ' $d$ ', and 'e' in Figure 1) [80]. Like most of the other studies [49], this research only investigated the effects of changes in temperature and rainfall, and climate stressors such as wind speed, percentage sunshine, and groundwater were not considered. Even though stressors such as wind speed may not be dominant for pavement performance, neglecting the groundwater level may lead to underestimated deterioration and, thus, maintenance costs [41,45]. Mallick et al. [81] developed a system dynamics approach to understand and quantify the further economic impact of climate change on highways. This study viewed climate change, pavement performance, and service life as a dynamic system integrating these multi-disciplinary topics (considered as arrows ' $a$ ' and ' $d$ ' in Figure 1). This method was first performed for section levels and was subsequently applied to road networks. The study estimated a $160 \%$ increase in maintenance costs by 2100 for thin asphalt pavements. These costs are of greater magnitude compared to other studies, e.g., Underwood et al. [48], probably due to the combined effects of increasing temperature and soil moisture in coastal regions (e.g., sea level rise).

Underwood et al. [48,82] estimated a U.S. national budget ranging between $\$ 19.0$ and $\$ 26.3$ billion by 2040 if the current material selection does not adapt to predicted climate. By 2070, the number will range between $\$ 21.8$ and $\$ 35.8$ billion. These studies are probably the most comprehensive network analysis so far, with consideration of downscaled general circulation climate models, traffic, structure, and materials (considered as arrows ' $a$ ', ' $d$ ', and ' $j$ ' in Figure 1). AASHTOWare Pavement ME Design (a newer version of MEPDG) was used for pavement performance modelling. Maintenance costs and maintenance cycles were considered to estimate the additional costs incurred by climate adaptation measures. Another study from the same author to supplement the selection of the general circulation models is described in Underwood et al. [83]. Although comprehensive, the studies made various simplifying assumptions, e.g., assumed traffic from typical values, generalized material properties, and simplified LCC components. These assumptions may add uncertainties in the analysis results and make them less specific/accurate at project levels. Therefore, there is an urgent need to further enhance the network level studies using site-specific traffic data, material properties, and more sophisticated LCC models. Again, none of these studies fully addressed the uncertainties from climate inputs and the modelling of the pavement system, which will lead to inaccuracy in analyses of performance, sensitivity, or costs.

Kottayi et al. [84] conducted a stochastic cost analysis to investigate the feasibility of climate adaptation measures, with sensitivity analysis and a Monte-Carlo simulation. The study adopted the sensitivity analysis to identify inputs that have larger influences on the estimated costs. Then, stochastic values for the identified influential inputs were used to evaluate the variabilities in the final cost estimations. This study demonstrated an uncertainty-based approach to quantify uncertainties in estimated costs of climate adaptation measures.

In recent years, risk-based approaches have been developed to establish frameworks to quantify environmental risks to pavements due to changes in climates. The concept of risk here is substantially different from the aforementioned concept of uncertainty. Uncertainty is caused by inaccuracies in modelling the interactive system and the sub-models (see Figure 1), while the risk is caused by an environmental hazard, e.g., extreme temperature or precipitation. Lu et al. [85] adopted a "performance-based" design approach, commonly seen in seismic design for structures, to quantify the environmental risk of extreme precipitation on pavements. This approach considered risk as the multiplication of the probability of extreme precipitation, the fragility of pavements to extreme 
precipitation, and the economic consequences on pavements. Both the uncertainty and the risk described above are unsolved parts of Figure 1 and need to be considered in future studies.

\subsection{Climate Change Adaptation Methodology}

Adaptation refers to the ability to change a highway system in order to adjust to climate change and reduce its vulnerability to climate stressors. Even though many studies have been performed to find methods for climate change mitigation, far less attention has been paid to adaptation [59]. Meyer and Weigel [86] reviewed climate change adaptation of transportation systems, considering subsurface conditions, material specifications, structures, drainage, and location engineering, and developed a six-step-method to identify vulnerability, risk, and costs of transportation systems. For pavements, local changes in high temperature, intensive rainfall, flooding, sea level rise, and freeze-thaw cycles need to be considered in climate adaptation designs.

In areas with increasing extreme temperatures, upgrading binder grade or increasing layer thickness in pavement design may be desirable [82,87]. In addition, where gaps between daily/monthly/seasonal high and low temperature increases, the choice of binder needs to be able to cover all extremes [88]. However, it may increase economic/environmental costs significantly when applying binder upgrading or increasing layer thickness at network levels $[89,90]$. The cost-effectiveness of these adaptation methods needs to be investigated in future studies [91].

Increasing precipitation frequency or intensity, within anticipated magnitudes, is generally not a major concern for life-cycle performance of flexible pavements, compared to extreme temperatures [50]. However, when it causes more frequent or intensive flooding, the impact can then become significant. When flooded, pavement unbound layers and subgrade can become saturated, and stiffness was found to reduce significantly [92]. As a result, the traffic bearing capacity and shear strength can also reduce significantly. In this case, it may be good adaptation practice to improve drainage or raise road surface levels to a higher level relative to the surrounding ground in areas where flooding is frequent, while considering its cost-efficiency $[93,94]$. In addition, use of fine materials in unbound granular layers needs to be reduced where precipitation and groundwater level will increase in the future [95]. This can help to reduce the capillary effects and thus help to reduce moisture content, especially where existing groundwater levels are high. Moreover, accidents related to pavement deterioration may occur more frequently and cost lives and money in areas where wetter pavement surfaces are expected due to climate change. In this case, porous asphalt can be used to provide a surface that is free of water and improve driving safety. However, porous asphalt is more prone to surface moisture damage, i.e., raveling and, thus, should be carefully designed when applied as an adaptation to climate change [96]. In addition, porous asphalt usually adopts additives to achieve better durability [97,98].

Pavement design in the future may also need to consider changes in induced traffic demand due to climate change (i.e., the indirect impact). For example, some coastal areas will be more prone to flooding when the sea level rises. As a consequence, local residents may move inland, where traffic demand may increase. Without considering this, the impacts of climate change can be underestimated [7]. Even though demographic changes are caused by various factors and can be difficult to quantify from place to place, qualitative studies on the indirect impacts, at least, need to be performed when assessing impacts of climate change on pavements.

Current maintenance practices usually consider a responsive approach, i.e., maintenance can be triggered by a particular type of distress, e.g., rutting. In this case, climate change can accelerate rutting development and, thus, will trigger maintenance earlier. A significant reduction of a pavement's service life due to climate change was found in some case studies [41,99]. At a network level, a significant amount of maintenance may be triggered much earlier. Clearly, this could have major implications for highways agencies' maintenance budgets. In order to avoid expensive costs, small relaxations in maintenance thresholds may be adopted by which additional deterioration is tolerated. In addition, research demonstrated that maintenance intervention optimization by minimizing total life-cycle costs can improve the resilience of highway sections against climate change [46]. Without changes to 
maintenance, additional deterioration due to climate change may lead to greater vehicle operating costs, including fuel consumption and vehicle repair costs.

An example of a, yet unassessed, impact of climate stressors on pavement deterioration is the impact on skidding resistance. It has been known for many years that wet pavement skidding resistance can decrease during summer months and recover during winter months [100] due to the interaction of environmental and traffic factors and the polishing of the microtexture of the surface. How this might be influenced by a changing climate has not yet been studied. Furthermore, high-speed wet skidding resistance is influenced by the texture depth of the pavement surface and has been shown to be adversely affected by low texture depths [101]. If hotter weather leads to the greater embedment of chips in an asphalt surface, this may contribute to a loss in wet skidding resistance, or the requirement for more frequent maintenance where a minimum texture depth is specified.

\subsection{Mitigation}

Pavements are not only affected by climate change but can also contribute to it. The reasons are two-fold. Firstly, a large amount of Greenhouse Gas (GHG) is emitted in various phases of a pavement's life cycles. In the U.S., transportation contributes a significant share (approximately $30 \%$, measured in 2006) of total domestic GHG emissions [102]. Highway transportation including trucks and passenger cars accounted for approximately $80 \%$ of GHG emissions of the whole transportation sector [102]. Therefore, it can be estimated that about $25 \%$ of total domestic GHG emissions are from highway users. In the 28 European Union member countries in 2012, the transportation share of domestic GHG emissions was $24.3 \%$, and the ratio of emissions from trucks and passenger cars to emissions of the whole transportation sector was $71.9 \%$, hence, the ratio of emissions from highway users to domestic GHG emissions was $17.5 \%$ [103]. Accordingly, any actions to the pavement that can reduce such emissions (like greater smoothness) will likely provide significant GHG warming mitigation on heavily trafficked roads. Secondly, asphalt roads cover large proportions of urban areas and can store and release more heat compared to soils, which can aggravate urban heat island effects [104]. Mitigation requires efforts to reduce highway GHG emissions over their life-cycle and to reduce pavements' heat storage capacity, as a contribution to slow down the process of climate change/urban warming.

Cool pavements have become more popular in research to alleviate urban heat island effects. Typically, this adaptation method is applied by overlaying existing pavements with a high reflective coating (i.e., high albedo coating) [105]. The coating enhances the reflection of solar energy and is found to reduce air temperatures near pavement surfaces [106]. A $17^{\circ} \mathrm{C}$ reduction of asphalt surface temperature was recorded by using such a coating in Singapore [107]. However, the reflected solar energy can warm up the surrounding built environment and, therefore, the application of the "cool" coating needs to take the surrounding environment into consideration [108,109]. Even though targeted at climate mitigation, the "cool" coating also seems to be a good climate adaptation measure. By significantly reducing pavement temperature, less rutting will be expected [107]. Permeable pavements are also found to have a "cooling" effect and can be used to alleviate the urban heat island effect. This is caused by the utilization of heat in the asphalt concrete as the latent heat of vaporization of water and, hence, the water is indispensable for this process [10]. Besides, permeable pavements can drain stormwater more rapidly and reduce the chance of pavements flooding. In addition, shading provided by buildings and trees can be advantageous as it is found to be effective in reducing pavement temperature and, thus, can reduce the surrounding temperature [109].

\subsection{Life-Cycle Assessment (LCA)}

Climate mitigation studies have focused, primarily, on quantifying the environmental impacts of highways, using a Life-Cycle Assessment (LCA) approach [110-114]. LCA has been used as a metric to evaluate and compare design and maintenance alternatives so that practices with lower life-cycle emissions can be identified either at the project level or the network level [115-117]. Pavement LCA is a huge subject and has been documented in various publications $[112,113,118]$. In this section, 
discussions are limited to general methodologies of pavement LCA within the boundary defined in Figure 1.

GHG emissions can occur in various phases of a pavement life cycle, including raw material acquisition, construction, transportation, operation, maintenance, and end of life recycling [112,118-121]. Practices with lower GHG emissions can be used as climate change mitigation methods:

(1) Many studies show the environmental benefits of Reclaimed Asphalt Pavement (RAP) in the recycling phase (e.g., [122-126]). The environmental benefits of RAP are greater when the recycling rate is higher. However, it is critical that the life-cycle performance of the RAP (particularly at high recycling rate) and service life will be evaluated and considered in LCA;

(2) Use of lower temperature asphalt is found to reduce environmental impacts in the construction phase (e.g., [127-129]). This encourages the use of cold or warm mix asphalt instead of hot mix asphalt to reduce energy consumption in material production and, hence, to reduce GHG emissions. However, care must be taken to avoid unintended consequences (e.g., high GHG emissions from use of additives, increased material transport distances, or maintenance frequencies), which should be assessed using LCA;

(3) On-site recycling usually has less GHG emissions compared to plant recycling due to saved GHG emissions in the transportation phase;

(4) Techniques have been suggested to select maintenance options based on pavement condition, LCA, and LCC (e.g., [130]). Preventive maintenance is typically cost-efficient and less energy intensive compared to, for example, rehabilitation. However, it does not improve pavement roughness and, thus, does not save emissions from vehicles traveling on the pavements.

Perhaps unsurprisingly, the results of LCA and LCA-based decision-making depend on the pre-defined LCA system boundary and the perspectives of different stakeholders. Moreover, it is important to consider the operation phase of a highway LCA due to the significance of user vehicle emissions (see arrows ' $\mathrm{e}$ ', ' $\mathrm{h}$ ', and ' $\mathrm{k}$ ' in Figure 1). For example, a "do nothing" maintenance strategy will lead to lower maintenance GHG emissions from materials and plants compared to a "do something" option. However, the "do nothing" strategy may lead to poorer highway serviceability, e.g., rolling resistance due to pavement roughness, or skid resistance [131,132]. This can cause higher user vehicle emissions in the operation phase, which can dominate the total life-cycle GHG emissions [133]. Increases in user fuel consumption due to pavement roughness have been estimated to be between about $1 \%$ and $6 \%[134,135]$. At the beginning of this section, the volume of GHG generated by vehicles was summarized. The volume that is directly attributable to the pavement construction and maintenance activity is tiny in comparison, although the indirect impact (e.g., by congestion caused by maintenance) may be more significant [102]. Therefore, mitigation effects in terms of improving fuel efficiency, promoting telecommuting, taxation changes, carpooling, etc. may have a much greater impact than changes to pavement design or pavement maintenance intervention regimes. However, it is important to optimize pavement design and maintenance so that user emissions can be minimized. It was concluded by many studies that it is worthwhile to invest in more durable pavements that have slower rates of deterioration. Even though the initial energy consumption, environmental impacts, and costs can be higher, the environmental impact can be lower over the long term [136].

In the literature, the LCA of pavement materials and on-site construction equipment is well documented [112]. However, a few gaps still exist to enable "full" life-cycle assessment of highways, including the operation phase, traffic delay, and salvage phase $[113,119,137]$. Huang and Parry $(2014)$ have recommended a checklist of actions to improve the comparability and transparency of road pavement LCA studies [115].

\subsection{Wider Consideration}

There are other opportunities to mitigate against climate change in the wider highway beyond the pavement (e.g., in using solar panels on noise barriers, or solar pavements, or to power electrical 
systems, or in the management of the green estate beyond the pavement), but these are beyond the scope of this review [12,138-141].

\subsection{Interactions between Adaptation and Mitigation}

As well as considering construction and materials issues, adaptation measures need to address current maintenance practices and pavement design to meet the demands of future climate conditions or demographic changes caused by climate change, in order to avoid costs associated with climate change (see "adaptation" in Figure 2). Furthermore, pavement design, maintenance (arrow ' $n$ ' in Figure 1), and use (arrow ' $\mathrm{o}$ ' in Figure 1) can be optimized to produce fewer greenhouse gases, which may help to alleviate climate change. Pavements and climate change require a partially coupled analysis to account for the interaction between the adaptation and mitigation methods under consideration (see Figure 2).

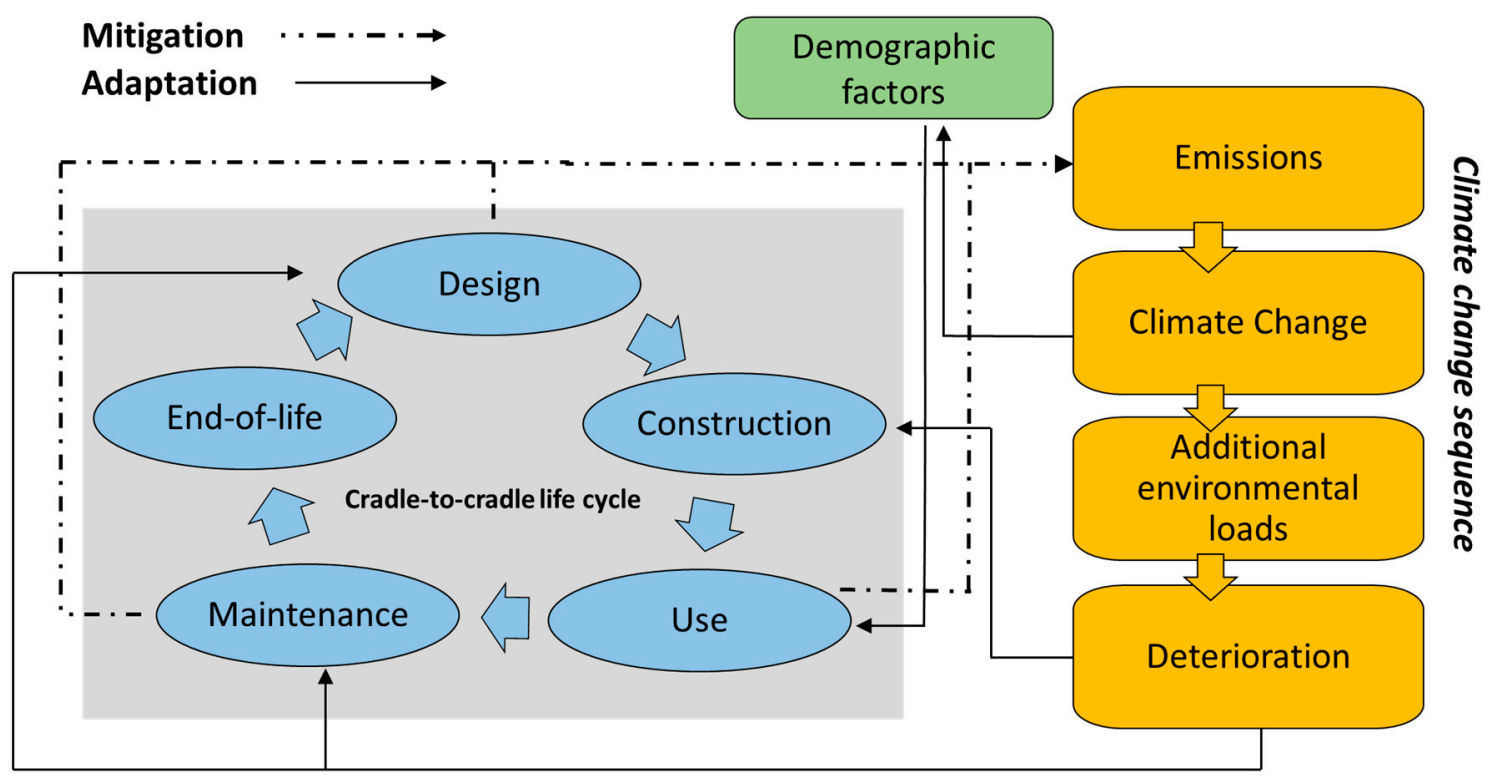

Figure 2. Pavement and climate change interaction.

As discussed earlier, climate change can add additional environmental loads to pavements, accelerating deterioration and impacting construction and maintenance. However, the response to this may lead to increases (or decreases) in GHG emissions and accelerate (or decelerate) climate change because, as summarized earlier, the transportation sector is a significant contributor to greenhouse gas emissions. Such interaction at the network level, thus, couples these effects. Current pavement construction and maintenance can be adapted to future climate in order to bear the extra environmental loading caused by climate change. The adaptation measures need to be targeted at improving road durability and serviceability. By doing so, they can reduce emissions and, thus, mitigate climate change. However, adaptation measures to improve durability and serviceability will certainly need modified procedures and practices and will likely require extra investment in the construction and maintenance of road infrastructure and, thus, are subject to budget constraints. Therefore, it is important to incorporate both Life-Cycle Cost Analysis (LCCA) and LCA methodology in the development of climate change adaptation and mitigation methods in order to minimize the "cradle-to-grave" economic and environmental impacts. When construction and maintenance budget is limited, the LCCA and LCA methodology can be combined and used to optimize achievable construction and maintenance targets, so as to maximize durability and serviceability and thus reduce emissions (or, at the very least, minimize them). 


\section{Conclusions}

Climate stressors can affect the interactions among flexible pavement performance, maintenance, and life-cycle costs. This review identified two types of methods for the assessment of climate change impacts, including the qualitative and quantitative methods that have been researched in the context of flexible pavements and climate change. The qualitative methods can be applied to identify various adaptation plans and the quantitative methods can be used to evaluate cost-benefits of a specific adaptation/mitigation plan. Based on the work reviewed in this study, the following conclusions can be drawn:

I. Early climate resilience assessment methodologies adopted qualitative risk assessment approaches. Development in pavement modelling tools allows for mechanistic-empirical modelling of pavement deterioration caused by climate change. Recent studies have attempted to evaluate potential economic benefit/loss caused by climate change at section or network levels.

II. The indirect effects of climate change, specifically changes in demography and traffic demand, seem likely to have large but, as yet, largely unquantified effects on pavement loading and, thus, on pavement life. Future studies should incorporate qualitative or quantitative techniques to assess this impact (Recommendation 1).

III. Various studies have supported the view that temperature, compared to other climatic factors, is the most influential for flexible pavement performance. Some climatic factors, e.g., groundwater level, can either be influential or not, depending on individual cases. Wind speed is a much less critical climate stressor compared to temperature. Even though these climatic factors need to be assessed case-by-case, there are some general findings:

i. High temperature is the greatest climate concern as flexible pavements are highly sensitive to high temperature, and the impacts can accumulate over the complete service life. Pavement design needs to consider changes in high temperature to adapt to future climate. Asphalt binder upgrading to adapt to greater temperature can be applicable, but its cost-effectiveness needs to be further investigated and justified (Recommendation 2).

ii. Changes in precipitation are of much less concern in a pavement life-cycle compared to temperature, unless it causes changes in flooding, storm surges, or a significant groundwater level rise. Future researches are needed to identify, locate, and quantify these impacts, e.g., quantifying pavement damage caused by flooding (Recommendation 3).

iii. In cold climates, it can be critical when climate change extends the spring thaw period. In these areas, (extended) spring vehicle load restrictions must be considered. Alternative pavement designs may need adopting at times of renewal. Otherwise, significant damage will occur on road networks.

IV. Pavement maintenance will be triggered earlier on significant road networks due to climate change. Road agencies need to be aware of this and be prepared for the much earlier arrival of maintenance budgets.

V. The highway transportation sector is a significant source of total anthropogenic GHG emissions, and highway LCA can be applied to plan GHG emission reductions and help mitigate climate change. Use of RAP, low temperature asphalt, on-site recycling, preventive maintenance, and high albedo coatings are typical practices for climate mitigation. Emissions from trucks and passenger cars during the use phase can be significant in total highway transportation GHG emissions and must be included in pavement LCA studies.

VI. Climate change can cause changes in pavement LCC, depending on changes in climate stressors, structure, and materials of the pavement maintenance regimes. Potentially, the total impacts of climate change on pavement performance, adaptation, and mitigation measures can be assessed 
based on the interaction of the climate-pavement system (Figures 1 and 2) so that optimal cost-effectiveness and environmental benefits can be achieved. This requires integrating LCCA and LCA methodology in developing cost-effective adaptation and sustainable mitigation measures. In addition, climate resilient and sustainable pavement design and management are multi-objective. They will not only need to adapt to the impacts of climate change but must also play a role in reducing GHG emissions. Future research in these areas is needed (Recommendation 4).

Author Contributions: Conceptualization, Y.Q., A.R.D., T.P., and G.F.; writing, Y.Q., A.R.D., T.P., and W.W.; revising, Y.Q., A.R.D., and W.W. All authors have read and agreed to the published version of the manuscript.

Funding: This research is funded by the China University of Mining and Technology (Grant number: 2020QN13). The authors gratefully acknowledge the financial support.

Conflicts of Interest: The authors declare no conflict of interest.

\section{References and Notes}

1. IPCC. Climate Change 2014: Synthesis Report. In Contribution of Working Groups I, II and III to the Fifth Assessment Report of the Intergovernmental Panel on Climate Change; Core Writing Team, Pachauri, R.K., Meyer, L.A., Eds.; IPCC: Geneva, Switzerland, 2014; 151p, Available online: https://www.ipcc.ch/site/assets/ uploads/2018/02/AR5_SYR_FINAL_Front_matters.pdf (accessed on 1 November 2018).

2. Berrang-Ford, L.; Pearce, T.; Ford, J.D. Systematic review approaches for climate change adaptation research. Reg. Environ. Chang. 2015, 15, 755-769. [CrossRef]

3. American Association of State Highway and Transportation Officials (AASHTO). Mechanistic-Empirical Pavement Design Guide (MEPDG), Version 1.1; National Cooperative Highway Research Program: Washington, DC, USA, 2009.

4. Thom, N.H.; Brown, S.F. Effect of moisture on the structural performance of a crushed-limestone road base. Transp. Res. Rec. 1987, 1121, 50-56.

5. Dawson, A.R. Anticipating and Responding to Pavement Performance as Climate Changes. In Climate Change, Energy, Sustainability and Pavements; Kasthurirangan, G., Wynand, J.S., Eds.; Springer: Berlin/Heidelberg, Germany, 2014; pp. 127-157.

6. Meyer, M.; Flood, M.; Dorney, C.; Leonard, K.; Hyman, R.; Smith, J. Climate Change and the Highway System: Impacts and Adaptation Approaches. Task 2.3; Synthesis report, NCHRP report 20-83; NCHRP: Washington, DC, USA, 2013.

7. Black, R.; Kniveton, D.; Skeldon, R.; Coppard, D.; Murata, A.; Schmidt-Verkert, K. Demographics and Climate Change: Future Trends and Their Policy Implications for Migration; Working paper; Development Research Centre on Migration, Globalisation and Poverty, University of Sussex: Brighton, UK, 2008.

8. Dawson, A.R. Rut Accumulation and Power Law Models for Low-volume Pavements under Mixed Traffic. Transp. Res. Rec. J. Transp. Res. Board. 2008, 2068, 78-86. [CrossRef]

9. Gui, J.; Phelan, P.; Kaloush, K.; Golden, J. Impact of Pavement Thermophysical Properties on Surface Temperatures. J. Mater. Civ. Eng. 2007, 19, 683-690. [CrossRef]

10. Li, H.; Harvey, J.; Kendall, A. Field Measurement of Albedo for Different Land Cover Materials and Effects on Thermal Performance. Build. Environ. 2013, 59, 536-546. [CrossRef]

11. Yavuzturk, C.; Ksaibati, K.; Chiasson, A. Assessment of Temperature Fluctuations in Asphalt Pavements Due to Thermal Environmental Conditions Using a Two-Dimensional, Transient Finite-Difference Approach. J. Mater. Civ. Eng. 2005, 17, 465-475. [CrossRef]

12. Mallick, R.B.; Chen, B.L.; Bhowmick, S.; Hulen, M. Capturing Solar Energy from Asphalt Pavements. International Symposium on Asphalt Pavements and Environment; International Society for Asphalt Pavements: Zurich, Switzerland, 2008.

13. Dawson, A.; Mallick, R.; Hernandez, A.G.; Dehdezi, P.K. Energy Harvesting from Pavements. In Climate Change, Energy, Sustainability and Pavements; Kasthurirangan, G., Wynand, J.S., Eds.; Springer: Berlin/Heidelberg, Germany, 2014; pp. 481-517.

14. Huang, Y.H. Pavement Analysis and Design; Pearson/Prentice Hall: Upper Saddle River, NJ, USA, 2004.

15. Thom, N. Principles of Pavement Engineering; Thomas Telford Ltd.: London, UK, 2008. 
16. Long, F.M. Permanent Deformation of Asphalt Concrete Pavements: A Nonlinear Viscoelastic Approach to Mix Analyses and Design. Ph.D. Thesis, University of California, Berkeley, CA, USA, 2001.

17. Lytton, R.L.; Shanmugham, U.; Garrett, B.D. Design of Asphalt Pavements for Thermal Fatigue Cracking. No. FHWA-TX-83-06+ 284-4 Interim Report; Texas Transportation Institute, Texas A\&M University: Arlington, TX, USA, 1983.

18. Dave, E.V.; Hoplin, C. Flexible Pavement Thermal Cracking Performance Sensitivity to Fracture Energy Variation of Asphalt Mixtures. Road Mater. Pavement Des. 2015, 16, 423-441. [CrossRef]

19. Yin, F.; Arámbula-Mercado, E.; Epps Martin, A.; Newcomb, D.; Tran, N. Long-term Ageing of Asphalt Mixtures. Road Mater. Pavement Des. 2017, 18, 2-27. [CrossRef]

20. Liu, P.; Hu, J.; Wang, H.; Canon, G.; Wang, D.; Oeser, M. Influence of Temperature on the Mechanical Response of Asphalt Mixtures Using Microstructural Analysis and Finite-element Simulations. J. Mater. Civ. Eng. 2018, 30, 04018327. [CrossRef]

21. Moreno-Navarro, F.; Sol-Sánchez, M.; García-Travé, G.; Rubio-Gámez, M.C. Fatigue Cracking in Asphalt Mixtures: The Effects of Ageing and Temperature. Road Mater. Pavement Des. 2018, 19, 561-570. [CrossRef]

22. Dempsey, B.J.; Elzeftawy, A. Moisture Movement and Moisture Equilibria in Pavement Systems; Project IHR-604; Illinois Cooperative Highways and Transportation Research Program; University of Illinois: Chicago, IL, USA, 1976.

23. Dawson, A.R. Water in Road Structures; Springer: Berlin, Germany, 2009.

24. Rotzoll, K.; Fletcher, C.H. Assessment of Groundwater Inundation as a Consequence of Sea-level Rise. Nat. Clim. Chang. 2013, 3, 477-481. [CrossRef]

25. Knott, J.; Daniel, J.; Jacobs, J.; Kirshen, P. Adaptation Planning to Mitigate Costal-Road Pavement Damage from Groundwater Rise Caused by Sea-Level Rise. Transp. Res. Rec. 2018. [CrossRef]

26. Dawson, A.R.; Wellner, F. Plastic Behaviour of Granular Materials. ARC Project 933. PRG99014; University of Nottingham: Nottingham, UK, 1999.

27. Korkiala-Tanttu, L. Calculation Method for Permanent Deformation of Unbound Pavement Materials. Ph.D. Thesis, Helsinki University of Technology, Helsinki, Finland, 2008.

28. Theyse, H.L. A Mechanical Design Model for Unbound Granular Pavement Layers. Ph.D. Thesis, University of Johannesburg, Johannesburg, South Africa, 2007.

29. Sol-Sánchez, M.; Moreno-Navarro, F.; García-Travé, G.; Rubio-Gámez, M.C. Laboratory Study of the Long-term Climatic Deterioration of Asphalt Mixtures. Constr. Build. Mater. 2015, 88, 32-40. [CrossRef]

30. Apeagyei, A.; Grenfell, J.R.; Airey, G.D. Influence of Aggregate Absorption and Diffusion Properties on Moisture Damage in Asphalt Mixtures. Road Mater. Pavement Des. 2015, 16, 404-422. [CrossRef]

31. Kandhal, P.; Rickards, I. Premature Failure of Asphalt Overlays from Stripping: Case Histories. Asphalt Paving Technol. 2001, 70, 301-351.

32. Zhang, J.; Apeagyei, A.K.; Airey, G.D.; Grenfell, J.R.A. Influence of aggregate mineralogical composition on water resistance of aggregate-bitumen adhesion. Int. J. Adhes. Adhes. 2015, 62, 45-54. [CrossRef]

33. Little, D.N.; Jones, D.R. Chemical and Mechanical Processes of Moisture Damage in Hot-Mix Asphalt Pavements. In Proceedings of the Transportation Research Board National Seminar, San Diego, CA, USA, 4-6 February 2003.

34. Salour, F. Moisture Influence on Structural Behaviour of Pavements. Ph.D. Thesis, School of Architecture and the Built Environment, Stockholm, Sweden, 2015.

35. Daniel, J.S.; Jacobs, J.M.; Miller, H.; Stoner, A.; Crowley, J.; Khalkhali, M.; Thomas, A. Climate change: Potential impacts on frost-thaw conditions and seasonal load restriction timing for low-volume roadways. Road Mater. Pavement Des. 2017, 19, 1-21. [CrossRef]

36. Chen, J.; Wang, H.; Xie, P. Pavement Temperature Prediction: Theoretical Models and Critical Affecting Factors. Appl. Therm. Eng. 2019, 158, 113755. [CrossRef]

37. Walker, C.L.; Anderson, M.R. Cloud Impacts on Pavement Temperature and Shortwave Radiation. J. Appl. Meteorol. Climatol. 2016, 55, 2329-2347. [CrossRef]

38. Qin, Y.; Hiller, J.E. Ways of Formulating Wind Speed in Heat Convection Significantly Influencing Pavement Temperature Prediction. Heat Mass Transf. 2013, 49, 745-752. [CrossRef]

39. Tighe, S.L.; Smith, J.; Mills, B.; Andrey, J. Using the MEPDG to Assess Climate Change Impacts on Southern Canadian Roads. In Proceedings of the 7th International Conference on Managing Pavement Assets, Calgary, AB, Canada, 23-28 June 2008. 
40. Mills, B.N.; Tighe, S.L.; Andrey, J.; Smith, J.T.; Huen, K. Climate Change Implications for Flexible Pavement Design and Performance in Southern Canada. J. Transp. Eng. 2009, 135, 773-782. [CrossRef]

41. Qiao, Y.; Flintsch, G.W.; Dawson, A.R.; Parry, T. Examining Effects of Climatic Factors on Flexible Pavement Performance and Service Life. Transp. Res. Rec. J. Transp. Res. Board. 2013, 2349, 100-107. [CrossRef]

42. Meagher, W.; Daniel, J.S.; Jacobs, J.; Linder, E. Method for Evaluating Implications of Climate Change for Design and Performance of Flexible Pavements. Transp. Res. Rec. 2012, 2305, 111-120. [CrossRef]

43. Yang, X.; You, Z.; Hiller, J.; Watkins, D. Sensitivity of flexible pavement design to Michigan's climatic inputs using pavement ME design. Int. J. Pavement Eng. 2017, 18, 622-632. [CrossRef]

44. Zapata, C.E.; Andrei, D.; Witczak, M.W.; Houston, W.N. Incorporation of Environmental Effects in Pavement Design. Road Mater. Pavement Des. 2007, 8, 667-693. [CrossRef]

45. Li, R.; Schwartz, C.W.; Forman, B. Sensitivity of Predicted Pavement Performance to Climate Characteristics. In Proceedings of the Airfield and Highway Pavement, Los Angeles, CA, USA, 18 June 2013. [CrossRef]

46. Qiao, Y. Flexible Pavements and Climate Change: Impact of Climate Change on the Performance, Maintenance, and Life-cycle Costs of Flexible Pavements. Ph.D. Thesis, University of Nottingham, Nottingham, UK, 2015.

47. Schwartz, C.W.; Li, R.; Ceylan, H.; Kim, S.; Gopalakrishnan, K. Global Sensitivity Analysis of Mechanistic-Empirical Performance Predictions for Flexible Pavements. Transp. Res. Rec. 2013, 2368, 12-23. [CrossRef]

48. Underwood, S.; Chester, M.; Gudipudi, P. Economic Impacts from Challenges in Pavement Engineering in an Uncertain Climate Future, Final Report for National Transportation Center at Maryland, NTC2016-SU-R-03. 2017.

49. Li, Q.; Mills, L.; McNeil, S. The Implications of Climate Change on Pavement Performance and Design; UDUTC Final Report; Delaware University Transportation Center: Newark, DE, USA, 2011.

50. Gudipudi, P.P.; Underwood, B.S.; Zalghout, A. Impact of Climate Change on Pavement Structural Performance in the United States. Transport. Res. Part D Transport. Environ. 2017, 57, 172-184. [CrossRef]

51. Hicks, R.G.; Seeds, S.B.; Peshkin, D.G. Select a Preventive Maintenance Treatment for Flexible Pavements; FHWA-IF-00-027; U.S. Department sf Transportation Federal Highway Administration: Washington, DC, USA, 2000.

52. Johanns, M.; Craig, J. Pavement Maintenance Manual. In Proceedings of Nebraska Department of Roads; Omaha, Nebraska, 2002.

53. DMRB. Pavement Design and Maintenance: Pavement Maintenance Assessment. Proceedings of Design Manual for Roads and Bridges, Highways England, 2016. Available online: http://www. standardsforhighways.co.uk/ha/standards/index.htm (accessed on 25 January 2020).

54. ISOHDM. Modelling Road Deterioration and Maintenance Effects in HDM-4. International Study of Highway Development and Management Tools. RETA 5549-REG Highway Development and Management Research, Final Reports. Vancouver, BC, Canada, 1995

55. Dave, E.V.; Song, S.H.; Buttlar, W.G.; Paulino, G.H. Reflective and Thermal Cracking Modelling of Asphalt Concrete. Adv. Charact. Pavement Soil Eng. Mater. 2007, 2, 1241-1252.

56. Zofka, A. Proactive Pavement Asset Management with Climate Change Aspects. IOP Conf. Ser. Mater. Sci. Eng. 2018, 365, 012005. [CrossRef]

57. Greenwood, I.D.; Christopher, R.B. HDM-4 Fuel Consumption Modelling. Draft report. 2003.

58. Chien, S.I.J.; Goulias, D.G.; Yahalom, S.; Chowdhury, S.M. Simulation-Based Estimates of Delays at Freeway Work Zones. J. Adv. Transp. 2002, 36, 131-156. [CrossRef]

59. TRB. Potential Impacts of Climate Change on U.S. Transportation; Special Report 290; Washington, DC, USA, 2008.

60. Dawson, A.R.; Carrera, A. Report 11-Overall Advice E Summary. Pavement Performance E Remediation Requirements following Climate Change; University of Nottingham: Nottingham, UK, 2010.

61. Meyer, M.; Flood, M.; Dorney, C.; Leonard, K.; Hyman, R.; Smith, J. Synthesis of Information on Projections of Climate Change in Regional Climates and Recommendation of Analysis Regions. National Cooperative Highway Research Project, NCHRP 20-83 (5), Task 2.4, 2013.

62. Strauch, R.L.; Raymond, C.L.; Rochefort, R.M.; Hamlet, A.F.; Lauver, C. Adapting Transportation to Climate Change on Federal Lands in Washington State, U.S.A. Clim. Chang. 2015, 130, 185-199. [CrossRef] 
63. Picketts, I.; Andrey, J.; Matthews, L.; Déry, S.; Tighe, S. Climate Change Adaptation Strategies for Transportation Infrastructure in Prince George, Canada. Reg. Environ. Chang. 2015, 16, 1109-1120. [CrossRef]

64. Daniel, J.S.; Jacobs, J.M.; Douglas, E.; Mallick, R.B.; Hayhoe, K. Impact of Climate Change on Pavement Performance: Preliminary Lessons Learned through the Infrastructure and Climate Network (ICNet). Clim. Eff. Pavement Geotech. Infrastruct. 2014, 1-9.

65. ICNet. The Infrastructure and Climate Network (ICNet). 2012. Available online: http://theicnet.org/ (accessed on 25 January 2020).

66. Markolf, S.A.; Hoehne, C.; Fraser, A.; Chester, M.V.; Underwood, B.S. Transportation Resilience to Climate Change and Extreme Weather Events-Beyond Risk and Robustness. Transp. Policy 2019, 74, 174-186. [CrossRef]

67. Mndawe, M.B.; Ndambuki, J.M.; Kupolati, W.K.; Badejo, A.A.; Dunbar, R. Assessment of the Effects of Climate Change on the Performance of Pavement Subgrade. Afr. J. Sci. Tech. Innov. Develop. 2015, 7, 111-115. [CrossRef]

68. Knott, J.F.; Jacobs, J.M.; Sias, J.E.; Kirshen, P.; Dave, E.V. A Framework for Introducing Climate-Change Adaptation in Pavement Management. Sustainability 2019, 11, 4382. [CrossRef]

69. Qiao, Y.; Santos, J.; Stoner, A.M.; Flinstch, G. Climate Change Impacts on Asphalt Road Pavement Construction and Maintenance: An Economic Life Cycle Assessment of Adaptation Measures in the State of Virginia, United States. J. Ind. Ecol. 2019, 1-14. [CrossRef]

70. Qiao, Y.; Dawson, A.; Parry, T.; Flintsch, G. Life Cycle Cost of Flexible Pavements and Climate Variability: Case Studies from Virginia. Struct. Infrastruct. Eng. 2019, 15, 1665-1679. [CrossRef]

71. Saha, J.; Nassiri, S.; Bayat, A.; Soleymani, H. Evaluation of the Effects of Canadian Climate Conditions on the MEPDG Predictions for Flexible Pavement Performance. Int. J. Pavement Eng. 2014, 15, 392-401. [CrossRef]

72. Elshaeb, M.A.; El-Badawy, S.M.; Shawaly, E.S.A. Development and Impact of the Egyptian Climatic Conditions on Flexible Pavement Performance. Am. J. Civ. Eng. Archit. 2014, 2, 115-121. [CrossRef]

73. Mohd Hasan, M.R.; Hiller, J.E.; You, Z. Effects of Mean Annual Temperature and Mean Annual Precipitation on the Performance of Flexible Pavement Using ME Design. Int. J. Pavement Eng. 2016, 17, 647-658. [CrossRef]

74. Nega, A.; Nikraz, H.; Herath, S.; Ghadimi, B. Distress Identification, Cost Analysis and Pavement Temperature Prediction for the Long-Term Pavement Performance for Western Australia. Int. J. Eng. Technol. 2015, 7, 267-275. [CrossRef]

75. Austroads. Impact of climate change on road infrastructure. APR-243, Sydney, 2004.

76. World-Bank. The Costs to Developing Countries of Adapting to Climate Change. Consultation Draft; The World Bank Group: Washington, DC, USA, 2010.

77. Chinowsky, P.; Schweikert, A.; Strzepek, N.; Manahan, K.; Strzepek, K.; Schlosser, A. Adaptation Advantage to Climate Change Impacts on Road Infrastructure in Africa Through 2011; Working paper; World Institute for Development Economics Research University of Colorado: Boulder, CO, USA, 2011.

78. Schweikert, A.; Chinowsky, P.; Kwiatkowski, K.; Espinet, X. The Infrastructure Planning Support System: Analyzing the Impact of Climate Change on Road Infrastructure and Development. Transp. Policy 2014, 35, 146-153. [CrossRef]

79. Houghton, N.; Styles, E. Future thinking: Exploring Future Scenarios for Climate Change and Effects on the National Highway System. In Proceedings of the 25th Australasian Transport Research Forum (ATRF), Canberra, Australia, 13 January 2002.

80. Odoki, J.B.; Kerali, H.G.R. Highway Development and Management. HDM-4 Technical Reference Manual; PIARC: Paris, France, 1999.

81. Mallick, R.; Radzicki, M.; Daniel, J.; Jacobs, J. Use of System Dynamics to Understand Long-Term Impact of Climate Change on Pavement Performance and Maintenance Cost. Transp. Res. Rec. J. Transp. Res. Board. 2014, 2455, 1-9. [CrossRef]

82. Underwood, S.; Guido, Z.; Gudipudi, P.; Feinberg, Y. Increased Costs to US Pavement Infrastructure from Future Temperature Rise. Nat. Clim. Chang. 2017, 7, 704-707. [CrossRef]

83. Underwood, S. A Method to Select General Circulation Models for Pavement Performance Evaluation. Int. J. Pavement Eng. 2019. [CrossRef] 
84. Kottayi, N.; Mallick, R.B.; Jacobs, J.M.; Daniel. Economics of Making Roadway Pavements Resilient to Climate Change: Use of Discounted Cash Flow and Real Options Analysis. J. Infrastruct. 2019, 25, 1-7. [CrossRef]

85. Lu, D.; Tighe, S.; Xie, W.-C. Pavement Risk Assessment for Future Extreme Precipitation Events under Climate Change. Transp. Res. Rec. J. Transp. Res. Board. 2018, 2672, 122-131. [CrossRef]

86. Meyer, M.; Weigel, B. Climate Change and Transportation Engineering: Preparing for a Sustainable Future. J. Transp. Eng. 2011, 137, 393-403. [CrossRef]

87. Wistuba, M.P.; Walther, A. Consideration of Climate Change in the Mechanistic Pavement Design. Road Mater. Pavement Des. 2013, 14, 227-241. [CrossRef]

88. Dave, E.V.; Buttlar, W.G.; Leon, S.E.; Behania, B.; Paulino, G.H. ILLiTC-low-temperature Cracking Model for Asphalt Pavements. Road Mater. Pavement Des. 2013, 14, 57-78. [CrossRef]

89. Chinowsky, P.S.; Price, J.C.; Neumann, J.E. Assessment of Climate Change Adaptation Costs for the U.S. Road Network. Glob. Environ. Chang. 2013, 23, 764-773. [CrossRef]

90. Chinowsky, P.; Scheikert, A.E.; Strzepek, N.L.; Strzepek, K. Road Infrastructure and Climate Change in Vietnam. Sustainability 2015, 7, 5452-5470. [CrossRef]

91. Moretti, L.; Loprencipe, G. Climate Change and Transport Infrastructures: State of the Art. Sustainability 2018, 10, 4098. [CrossRef]

92. Zhang, Z.; Wu, Z.; Martinez, M.; Gaspard, K. Pavement Structures Damage Caused by Hurricane Katrina Flooding. J. Geotech. Geoenviron. Eng. 2008, 134, 633-643. [CrossRef]

93. Kirshen, P.; Caputo, L.; Vogel, R.M.; Mathisen, P.; Rosner, A.; Renaud, T. Adapting Urban Infrastructure to Climate Change: A Drainage Case Study. ISO: J. Water Resour. Plan. Manag. ASCE 2014, 141, 4. [CrossRef]

94. Qiao, Y.; Medina, R.A.; McCarthy, L.M.; Mallick, R.B.; Daniel, J.S. Decision Tree for Postflooding Roadway Operations. Transp. Res. Rec. 2017, 2604, 120-130. [CrossRef]

95. FHWA. Climate Change Adaptation for Pavements. Federal Highway Administration, TechBrief, FHWA-HIF-15-015. 2015.

96. Kwiatkowski, K.P.; Oslakovic, I.S.; Maat, H.W.; Hartmann, A.; Chinowsky, P.; Dewulf, G.P.M.R. Climate Change Adaptation and Roads: Dutch Case Study of Cost Impacts at the Organization Level. In Proceedings of the Engineering Project Organization Conference, Vail, CO, USA, 9-11 July 2013.

97. Giustozzi, F. Polymer-modified Pervious Concrete for Durable and Sustainable Transportation Infrastructures. Constr. Build. Mater. 2016, 111, 502-512. [CrossRef]

98. Lu, G.; Liu, P.; Wang, Y.; Faßbender, S.; Wang, D.; Oeser, M. Development of a Sustainable Pervious Pavement Material Using Recycled Ceramic Aggregate and Bio-based Polyurethane Binder. J. Clean. Prod. 2019, 220, 1052-1060. [CrossRef]

99. Stoner, A.; Daniel, J.S.; Jacobs, J.M.; Hayhoe, K.; Scott-Fleming, I. Quantifying the Impact of Climate Change on Flexible Pavement Performance and Lifetime in the United States. Transp. Res. Rec. J. Transp. Res. Board. 2019, 2673, 110-122. [CrossRef]

100. Hosking, J.R.; Woodford, G.C. Measurement of Skidding Resistance Part II. Factors Affecting the Slipperiness of a Road Surface. TRRL Laboratory Report 738.TRL; Wokingham, UK, 1976.

101. Roe, P.G.; Parry, A.R.; Viner, H.E. High and Low Speed Skidding Resistance: The Influence of Texture Depth. TRL Report 367.TRL; Wokingham, UK, 1998.

102. Transportation and Greenhouse Gas Emissions. Available online: http://climate.dot.gov/about/ transportations-role/overview.html (accessed on 31 March 2016).

103. European Commission. Reducing Emissions from Transport. 2012. Available online: https://ec.europa.eu/ (accessed on 29 January 2020).

104. Asaeda, T.; Ca, V.T.; Wake, A. Heat Storage of Pavement and Its Effect on the Lower Atmosphere. Atmos. Environ. 1986, 30, 413-427. [CrossRef]

105. Kyriakodis, G.-E.; Santamouris, M. Using Reflective Pavements to Mitigate Urban Heat Island in Warm Climates-Results from a Large Scale Urban Mitigation Project. Urban Clim. 2018, 24, 326-339. [CrossRef]

106. Kinouchi, T.; Yoshinaka, T.; Fukae, N.; Kanda, M. Development of Cool Pavement with Dark Colored High Albedo Coating. In Proceedings of the American Meteorological Society, 5th Conference on Urban Environment, Vancouver, BC, Canada, 23-28 August 2004.

107. Wan, W.C.; Hien, W.N.; Ping, T.P.; Aloysius, A.Z.W. A Study on the Effectiveness of Heat Mitigating Pavement Coatings in Singapore. J. Heat Isl. Inst. Intl. 2012, 7, 238-247. 
108. Yang, J.; Wang, Z.H.; Kaloush, K.E. Environmental Impacts of Reflective Materials: Is High Albedo a 'Silver Bullet' for Mitigating Urban Heat Island? Renew. Sustain. Energy Rev. 2015, 47, 830-843. [CrossRef]

109. Battisti, A.; Laureti, F.; Zinzi, M.; Volpicelli, G. Climate Mitigation and Adaptation Strategies for Roofs and Pavements: A Case Study at Sapienza University Campus. Sustainability 2018, 10, 3788. [CrossRef]

110. Chiu, C.T.; Hsu, T.H.; Yang, W.F. Life Cycle Assessment on Using Recycled Materials for Rehabilitating Asphalt Pavements. Resour. Conserv. Recycl. 2008, 52, 545-556. [CrossRef]

111. Huang, Y.; Bird, R.; Heidrich, O. Development of a Life Cycle Assessment Tool for Construction and Maintenance of Asphalt Pavements. J. Clean. Prod. 2009, 17, 283-296. [CrossRef]

112. Santero, N.J.; Masanet, E.; Horvath, A. Life-cycle Assessment of Pavements. Part I: Critical Review. Resour. Conserv. Recycl. 2011, 55, 801-809. [CrossRef]

113. Santero, N.J.; Masanet, E.; Horvath, A. Life-cycle Assessment of Pavements Part II: Filling the Research Gaps. Resour. Conserv. Recycl. 2011, 55, 810-818. [CrossRef]

114. Yu, B.; Lu, Q. Life Cycle Assessment of Pavement: Methodology and Case Study. Transport. Res. Part D-Transport. Environ. 2012, 17, 380-388. [CrossRef]

115. Huang, Y.; Parry, T. Pavement Life Cycle Assessment. In Climate Change, Energy, Sustainability and Pavements; Kasthurirangan, G., Wynand, J.S., Eds.; Springer: Berlin/Heidelberg, Germany, 2014; pp. 1-40.

116. Gosse, C.; Smith, B. Environmentally Preferable Pavement Management Systems. J. Infrastruct. Syst. 2013, 19, 315-325. [CrossRef]

117. Reger, D.; Madanat, S.; Horvath, A. The Effect of Agency Budgets on Minimizing Greenhouse Gas Emissions from Road Rehabilitation Policies. Environ. Res. Lett. 2015, 10, 114007. [CrossRef]

118. Huang, Y.; Spray, A.; Parry, T. Sensitivity Analysis of Methodological Choices in Road Pavement LCA. Int. J. Life Cycle Assess. 2013, 18, 93-101. [CrossRef]

119. Harvey, J.; Wang, T.; Lea, J. Application of LCA Results to Network-Level Highway Pavement Management. In Climate Change, Energy, Sustainability and Pavements; Kasthurirangan, G., Wynand, J.S., Eds.; Springer: Berlin/Heidelberg, Germany, 2014; pp. 41-73.

120. Robinette, C.; Epps, J. Energy, Emissions, Material Conservation, and Prices associated with Construction, Rehabilitation, and Material Alternatives for Flexible Pavement. Transp. Res. Rec. J. Transp. Res. Board. 2010, 2179, 10-22. [CrossRef]

121. Santos, J.M.; Flintsch, G.W.; Ferreira, A. Environmental and Economic Assessment of Pavement Construction and Management Practices for Enhancing Pavement Sustainability. Resour. Conserv. Recycl. 2017, 116, $15-31$. [CrossRef]

122. Miliutenko, S.; Bjorklund, A.; Carlsson, A. Opportunities for Environmentally Improved Asphalt Recycling: The Example of Sweden. J. Clean. Prod. 2013, 43, 156-165. [CrossRef]

123. Aurangzeb, Q.; Al-Qadi, I.; Ozer, H.; Yang, R. Hybrid Life Cycle Assessment for Asphalt Mixtures with High RAP Content. Resour. Conserv. Recycl. 2014, 83, 77-86. [CrossRef]

124. Araújo, J.P.C.; Oliveira, J.R.; Silva, H.M. The Importance of the Use Phase on the LCA of Environmentally Friendly Solutions for Asphalt Road Pavements. Transport. Res. Part D Transport. Environ. 2014, 32, 97-110. [CrossRef]

125. Santos, J.; Bryce, J.; Flintsch, G.W.; Ferreira, A.; Diefenderfer, B. A Life Cycle Assessment of In-place Recycling and Conventional Pavement Construction and Maintenance Practices. Str. Infrastruct. Eng. Maint Manag. Life-Cycle Des. Perform. 2014, 1-20. [CrossRef]

126. Gu, F.; Ma, W.; West, R.C.; Taylor, A.J.; Zhang, Y. Structural Performance and Sustainability Assessment of Cold Central-plant and In-place Recycled Asphalt Pavements: A Case Study. J. Clean. Prod. 2019, 208, 1513-1523. [CrossRef]

127. Capitao, S.D.; Picado-Santos, L.G.; Martinho, F. Pavement Engineering Materials: Review on the Use of Warm-mix Asphalt. Constr. Build. Mater. 2012, 36, 1016-1024. [CrossRef]

128. Del Carmen Rubio, M.; Moreno, F.; Martínez-Echevarría, M.J.; Martínez, G.; Vázquez, J.M. Comparative Analysis of Emissions from the Manufacture and Use of Hot and Half-warm Mix Asphalt. J. Clean. Prod. 2013, 41, 1-6. [CrossRef]

129. Giani, M.I.; Dotelli, G.; Brandini, N.; Zampori, L. Comparative life cycle assessment of asphalt pavements using reclaimed asphalt, warm mix technology and cold in-place recycling. Resour. Conserv. Recycl. 2015, 104, 224-238. [CrossRef] 
130. Bryce, J.M.; Flintsch, G.; Hall, R.P. A Multi Criteria Decision Analysis Technique for Including Environmental Impacts in Sustainable Infrastructure Management Business Practices. Transport. Res. Part D Transport. Environ. 2014, 32, 435-445. [CrossRef]

131. Wang, T.; Lee, I.S.; Kendall, A.; Harvey, J.; Lee, E.B.; Kim, C. Life Cycle Energy Consumption and GHG Emission from Pavement Rehabilitation with Different Rolling Resistance. J. Clean. Prod. 2012, 33, 86-96. [CrossRef]

132. Trupia, L.; Parry, T.; Neves, L.; Lo Presti, D. Rolling Resistance Contribution to a Road Pavement Life Cycle Carbon Footprint Analysis. Int. J. Life Cycle Assess. 2017, 22, 972-985. [CrossRef]

133. Kang, S.; Yang, R.; Ozer, H.; Al-Qadi, I. Life-cycle Greenhouse Gases and Energy Consumption for Material and Construction Phases of Pavement with Traffic Delay. Transp. Res. Rec. 2014, 2428, 27-34. [CrossRef]

134. Laganier, R.; Lucas, J. The Influence of Pavement Evenness and Macrotexture on Fuel Consumption. Surface Characteristics of Roadways: International Research and Technologies; ASTM STP 1031; ASTM International: Philadelphia, PA, USA, 1990; pp. 454-459.

135. Sandberg, U. Road Macro and Mega Texture Influence on Fuel Consumption. Surface Characteristics of Roadways: International Research and Technologies; ASTM STP 1031; ASTM International: Philadelphia, PA, USA, 1990; pp. $460-479$.

136. Lidicker, J.; Sathaye, N.; Madanat, S.; Horvath, A. Pavement Resurfacing Policy for Minimization of Life-cycle Costs and Greenhouse Gas Emissions. J. Infrastruct. Syst. 2012, 19, 129-137. [CrossRef]

137. Galatioto, F.; Huang, Y.; Parry, T.; Bird, R.; Bell, M. Traffic Modelling in System Boundary Expansion of Road Pavement Life Cycle Assessment. Transport. Res. Part D Transport. Environ. 2015, 36, 65-75. [CrossRef]

138. Carder, D.R.; Hawker, L.; Parry, A.R. Motorway Noise Barriers as Solar Power Generators. Proc. Inst. Civ. Eng.-Eng. Sustain. 2007, 160, 17-26. [CrossRef]

139. Van Bijsterveld, W.; Houben, L.; Scarpas, A.; Molenaar, A. Using Pavement as Solar Collector: Effect on Pavement Temperature and Structural Response. Transp. Res. Rec. J. Transp. Res. Board. 2001, 1778, 140-148. [CrossRef]

140. Carder, D.R.; Barker, K.J.; Hewitt, M.G.; Ritter, D.; Kiff, A. Performance of an Interseasonal Heat Transfer Facility for Collection, Storage and Re-use of Solar Heat from the Road Surface. PPR302. TRL. Wokingham, UK, 2008.

141. Bobes-Jones, V.; Pascual-Munoz, P.; Castro-Fresno, D.; Rodriguez-Hernandez, J. Asphalt Solar Collectors: A Literature Review. Appl. Energy. 2013, 102, 962-970. [CrossRef] 